\title{
Critical Learning Skills For Business Students
}

Marsha Jance, Indiana University East, USA

Anita Morgan, Indiana University East, USA

\begin{abstract}
A survey addressing critical skills for business students was developed and disseminated. Sixteen critical skills (such as critical thinking and time management) were identified as skills that need to be acquired in order for business students to be successful in their advanced courses and careers. The survey was disseminated and taken by several business faculty at various institutions. The survey participants were asked to rank both the importance of a particular skill and where their students currently rank in possessing this skill. This paper discusses the format of the survey, presents the survey results, analyzes the top three critical skills, and mentions future research opportunities.
\end{abstract}

Keywords: Critical Learning Skills; Business Students

\section{INTRODUCTION}

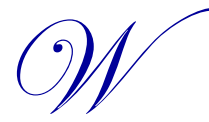

hat are "the" critical skills that business students need in order to be successful in their advanced coursework and careers? This is a question that has come up frequently at faculty meetings, conferences, and other events where curriculum and needed skill sets for employment are discussed. The authors, who have taught courses in business, accounting, statistics, and first year seminar, have had multiple discussions regarding critical skills needed for business students and how to go about teaching and assessing these skills in their courses. The authors identified sixteen critical skills as vital to business student success and were curious to see how other faculty at various institutions would rank the importance of these skills and their perceptions of where their students currently rank in terms of possessing these skills.

An IRB approved survey was developed by the authors to help assess what are the most important critical skills needed by business students in order for them to succeed in their advanced courses and careers. This online survey was sent to business faculty at two and four year private and public institutions. The participants were asked to rank the importance of a particular skill on a scale from one (1) to ten (10) with ten being the most critical. In addition, participants were asked to indicate where their students currently rank in terms of possessing a particular skill.

This paper first provides an overview of the survey and then looks at the survey results. In addition, the top three critical skills are analyzed in more detail. Finally, some future research opportunities are explored and conclusions are provided.

\section{OVERVIEW OF THE SURVEY}

The survey asked participants to provide the following faculty and institution information:

- $\quad$ Areas of teaching

- Number of years teaching

- $\quad$ The approximate number of students enrolled in their business school (college/department/division)

- Whether they primarily teach at a private or public institution

- Whether they primarily teach at a two year or four year institution

(C) 2013 The Clute Institute http://www.cluteinstitute.com/ 
The survey then provided a list of critical skills and asked participants to rank the importance of a particular skill and where their students currently rank in terms of possessing this skill. Table 1 shows the sixteen critical skills (e.g. critical thinking, time management) that were listed in the survey. Survey participants were asked to rank each skill on a scale from one (1) to ten (10) with one (1) being the least critical and ten (10) being the most critical. In addition, a comment box was also provided in the survey for participants to include additional critical skills that they deem important for student success.

Table 1: Critical Skills for Business Students

\begin{tabular}{|c|c|c|}
\hline 1. & Critical thinking & 2. $\quad$ Summarizing without plagiarizing \\
\hline 3. & Searching for information & Knowing how to use presentation software \\
\hline 5. & Knowing how to use spreadsheet software & Knowing how to use word processing software \\
\hline 7. & $\begin{array}{l}\text { Knowing how to use campus computer } \\
\text { applications }\end{array}$ & 8. Reading comprehension \\
\hline & Effective written communication & 10. Oral presentation \\
\hline 11. & Professionalism & 12. Quantitative skills \\
\hline 13. & Financial literacy & 14. Awareness of current business events \\
\hline 15. & Time management & 16. Career planning \\
\hline
\end{tabular}

\section{SURVEY RESULTS}

The survey participants provided both faculty and institution information. Figure 1 presents the primary teaching areas and Figure 2 shows the number of years that survey participants have been teaching. According to Figure 1, the majority of the participants teach management courses (65.63\%). Accounting and entrepreneurship came in second in terms of primary teaching areas. In addition, the survey participants also indicated in the comments section that they teach freshman seminar, project management, law and ethics, general business, operations management, supply chain management, and leadership courses. According to Figure 2, approximately $71 \%$ of the survey participants have been teaching between 7 to 24 years. The largest groups are those who have been teaching between 7 to 12 years and 19 to 24 years.

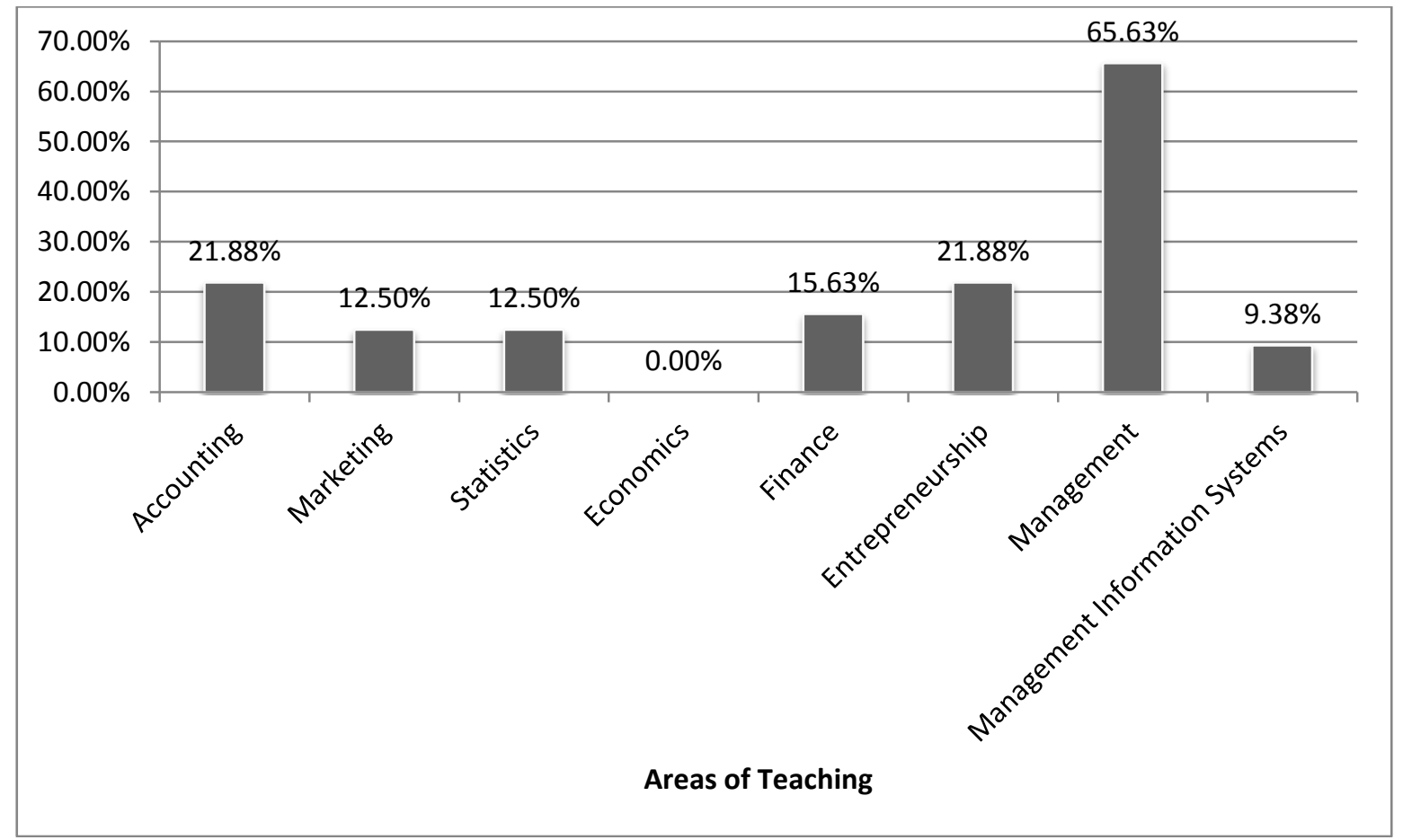

Figure 1: Areas of Teaching 


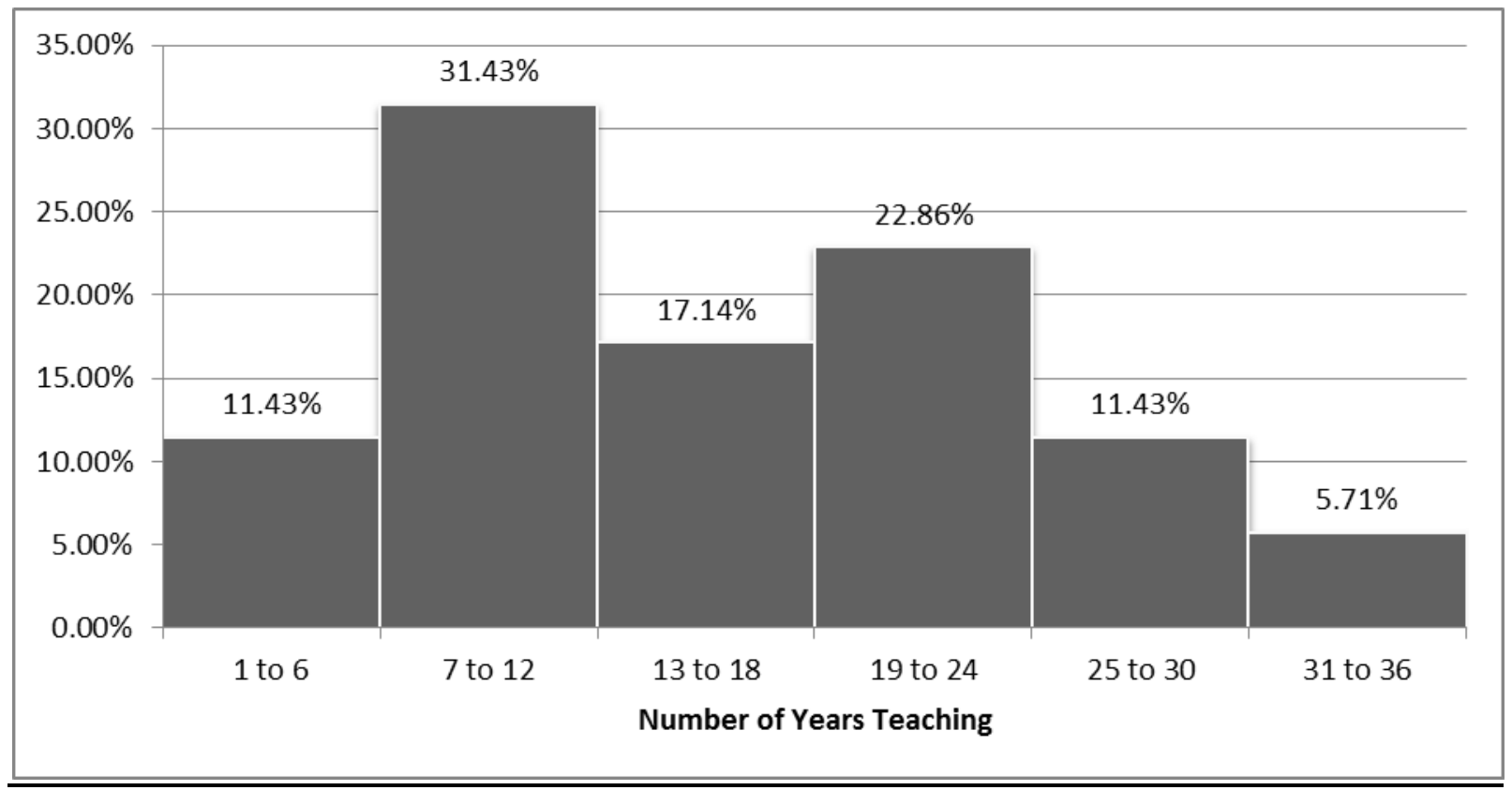

Figure 2: Number of Years Teaching

The participants also indicated the approximate number of students enrolled in their business school (college/division/department) and whether they teach primarily at two or four year private or public institutions. Figure 3 shows the results for the approximate number of business students enrolled at the institutions. The largest group is 200 to 399 business students enrolled. In addition, approximately 43\% have between 600 to 1199 business students enrolled at their institutions. There is a fairly even distribution among private and public institution participants. According to the results, $48.57 \%$ of the participants teach at private institutions and $51.43 \%$ teach at public institutions. In addition, $70.59 \%$ of the participants teach at four year institutions compared to $29.41 \%$ that teach at two year institutions.

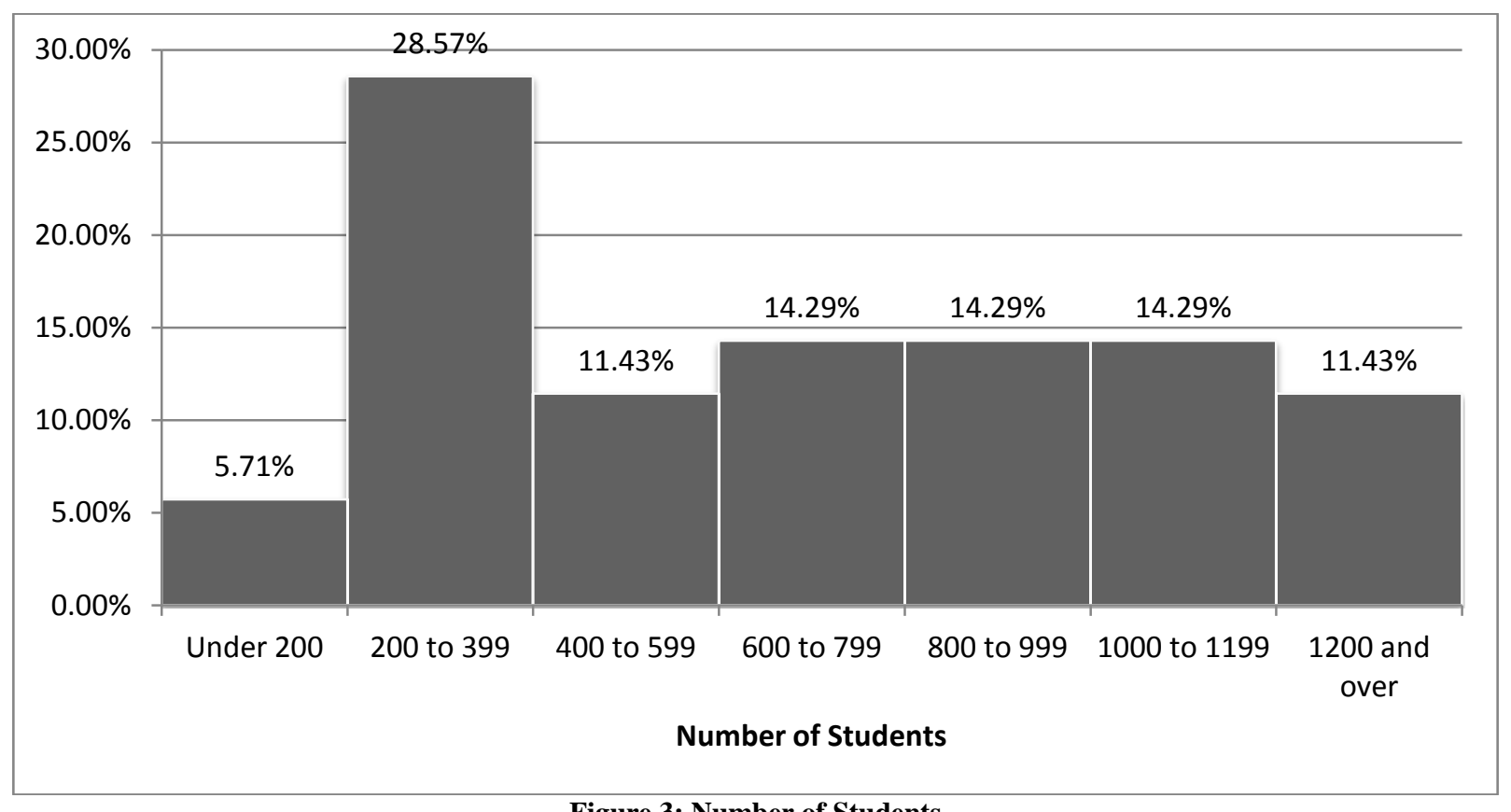

Figure 3: Number of Students 
Survey participants were asked to rank the importance of each skill on a scale from one (1) to ten (10) with ten being the most critical. A comments box was also provided in the survey for participants to add other critical skills that they deem important for student success. Participants indicated that these additional critical skills are important: logical reasoning, organizational skills, foreign language skills, the ability to work in teams, and accountability.

A weighted average was calculated for the rankings in terms of importance for each of the critical skills. Figure 4 and Table 2 show the weighted average of importance for the critical skills. The top three critical skills are critical thinking, reading comprehension, and effective written communication with weighted averages of 9.14, 9.11, and 9.03 respectively. The lowest ranked critical skills are knowing how to use presentation software, financial literacy, and career planning with weighted averages of 7.11, 7.46, and 7.50 respectively. However, it is interesting to note that all of the skills have weighted average scores greater than 7.00. Therefore, the faculty surveyed perceive that all 16 critical skills are important to student success.

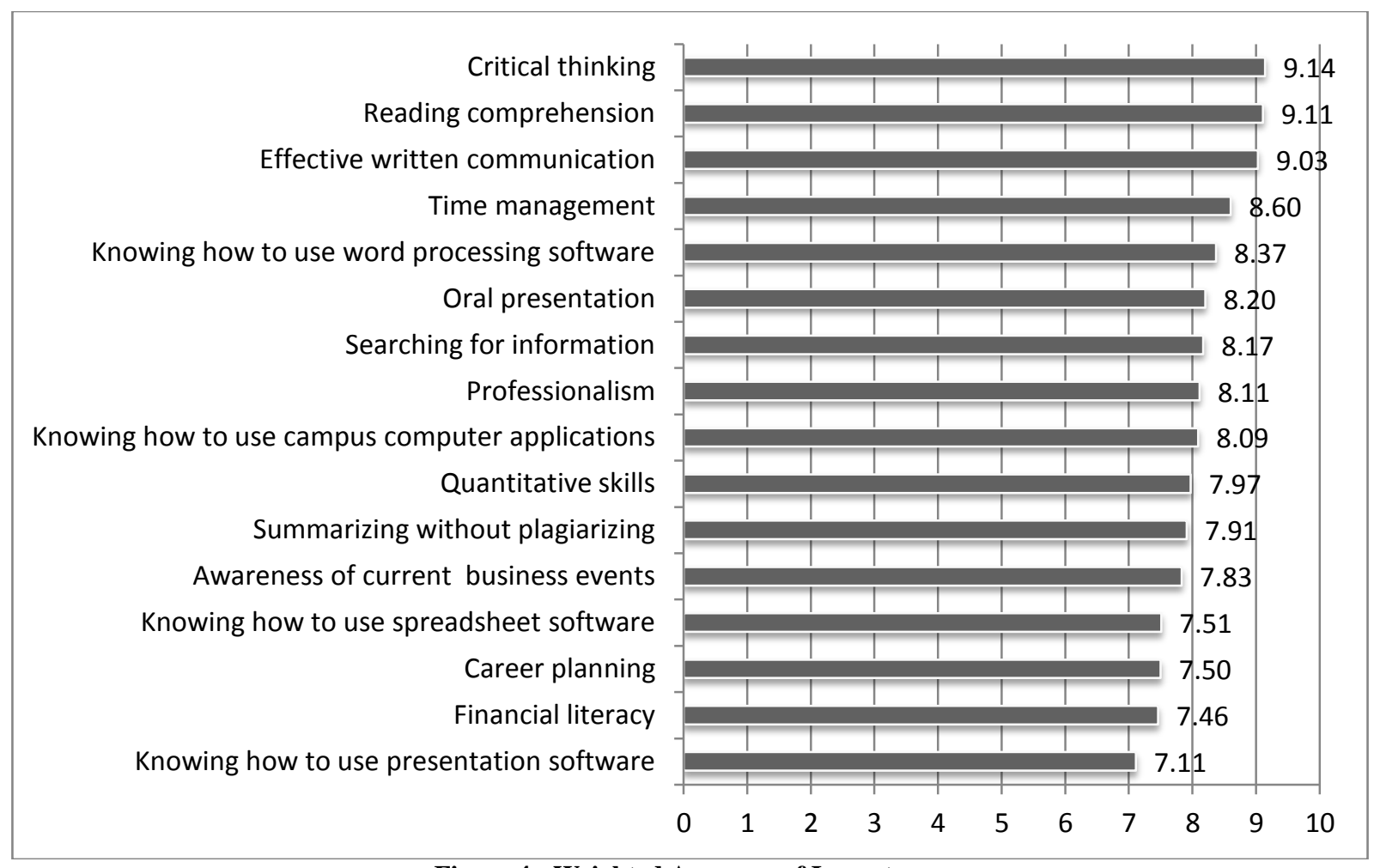

Figure 4: Weighted Averages of Importance

Survey participants were also asked to rate where their students currently rank in possessing a particular skill on a scale from one (1) to ten (10) with ten being the highest in terms of possessing the skill. The weighted average of the rankings of current student ability level for each critical skill was calculated from the participant responses. Figure 5 and Table 2 show the weighted average of where students currently rank in possessing a particular skill. The top three skills are knowing how to use word processing software, presentation software, and campus computer applications with weighted averages of 7.97, 7.29, and 7.15 respectively. The lowest ranked skills are awareness of current business events, career planning, and financial literacy with weighted averages of 4.47, 4.75 , and 4.79 respectively. 
Table 2: Weighted Averages

\begin{tabular}{|c|c|c|c|}
\hline Critical Skill & $\begin{array}{l}\text { Weighted Average } \\
\text { of Importance }\end{array}$ & $\begin{array}{c}\text { Weighted Average of } \\
\text { Where Students Currently Rank in } \\
\text { Terms of Possessing this Skill } \\
\end{array}$ & Difference \\
\hline Critical thinking & 9.14 & 5.94 & 3.20 \\
\hline Reading comprehension & 9.11 & 5.88 & 3.23 \\
\hline Effective written communication & 9.03 & 5.50 & 3.53 \\
\hline Time management & 8.60 & 5.21 & 3.39 \\
\hline Knowing how to use word processing software & 8.37 & 7.97 & 0.40 \\
\hline Oral presentation & 8.20 & 5.65 & 2.55 \\
\hline Searching for information & 8.17 & 5.88 & 2.29 \\
\hline Professionalism & 8.11 & 5.71 & 2.40 \\
\hline $\begin{array}{l}\text { Knowing how to use campus computer } \\
\text { applications }\end{array}$ & 8.09 & 7.15 & 0.94 \\
\hline Quantitative skills & 7.97 & 4.94 & 3.03 \\
\hline Summarizing without plagiarizing & 7.91 & 5.44 & 2.47 \\
\hline Awareness of current business events & 7.83 & 4.47 & 3.36 \\
\hline Knowing how to use spreadsheet software & 7.51 & 5.74 & 1.77 \\
\hline Career planning & 7.50 & 4.75 & 2.75 \\
\hline Financial literacy & 7.46 & 4.79 & 2.67 \\
\hline Knowing how to use presentation software & 7.11 & 7.29 & -0.18 \\
\hline
\end{tabular}

Knowing how to use word processing software Knowing how to use presentation software Knowing how to use campus computer applications

Critical thinking Searching for information Reading comprehension Knowing how to use spreadsheet software Professionalism Oral presentation Effective written communication Summarizing without plagiarizing Time management Quantitative skills Financial literacy Career planning Awareness of current business events

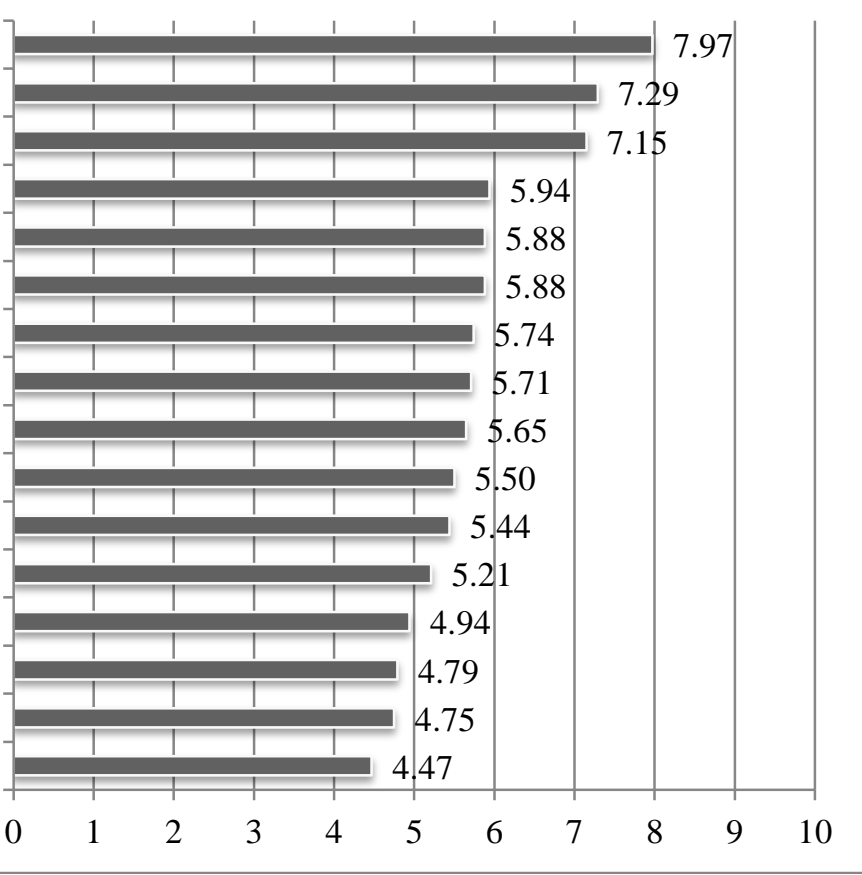

Figure 5: Weighted Averages of Where Students Currently Rank in Terms of Possessing a Particular Skill

Table 2 also shows the difference between the weighted average of importance and the weighted average of where students currently rank in terms of possessing a particular skill. For example, in terms of critical thinking the weighted average of importance is 9.14 and the weighted average of where students currently rank is 5.94 thereby a difference of 3.20. The weighted average of importance is higher than the weighted average of where students currently rank for all critical skills except for the skill knowing how to use presentation software. The major differences occur for the skills: effective written communication (3.53), time management (3.39), awareness of current business events (3.36), reading comprehension (3.23), and critical thinking (3.20). 


\section{TOP THREE CRITICAL SKILLS}

The survey results show that the top three skills deemed the most critical by faculty are critical thinking, reading comprehension, and effective written communication. Also, these three skills saw quite a spread in terms of importance and where students currently rank in possessing these skills. Figures 6, 7, and 8 show in more detail the percentage of how faculty ranked the importance of the skills and where their students currently rank in possessing these skills. One will notice from these figures that for all three skills, over $65 \%$ of the faculty gave a 10 with others giving mostly $8 \mathrm{~s}$ and $9 \mathrm{~s}$ in terms of importance.

However, one will also notice that while these skills were given high rankings in terms of importance, students still have some ways to go in terms of acquiring these skills. For critical thinking and effective written communication, most respondents gave their students a 5 or 6 in terms of where they (students) currently rank in possessing these skills. For reading comprehension, the majority of the respondents gave a 5, 6, or 7 in terms of where their students currently rank in possessing this skill. It appears that work still needs to be done in order to help students improve their critical thinking, reading comprehension, and written communication skills.

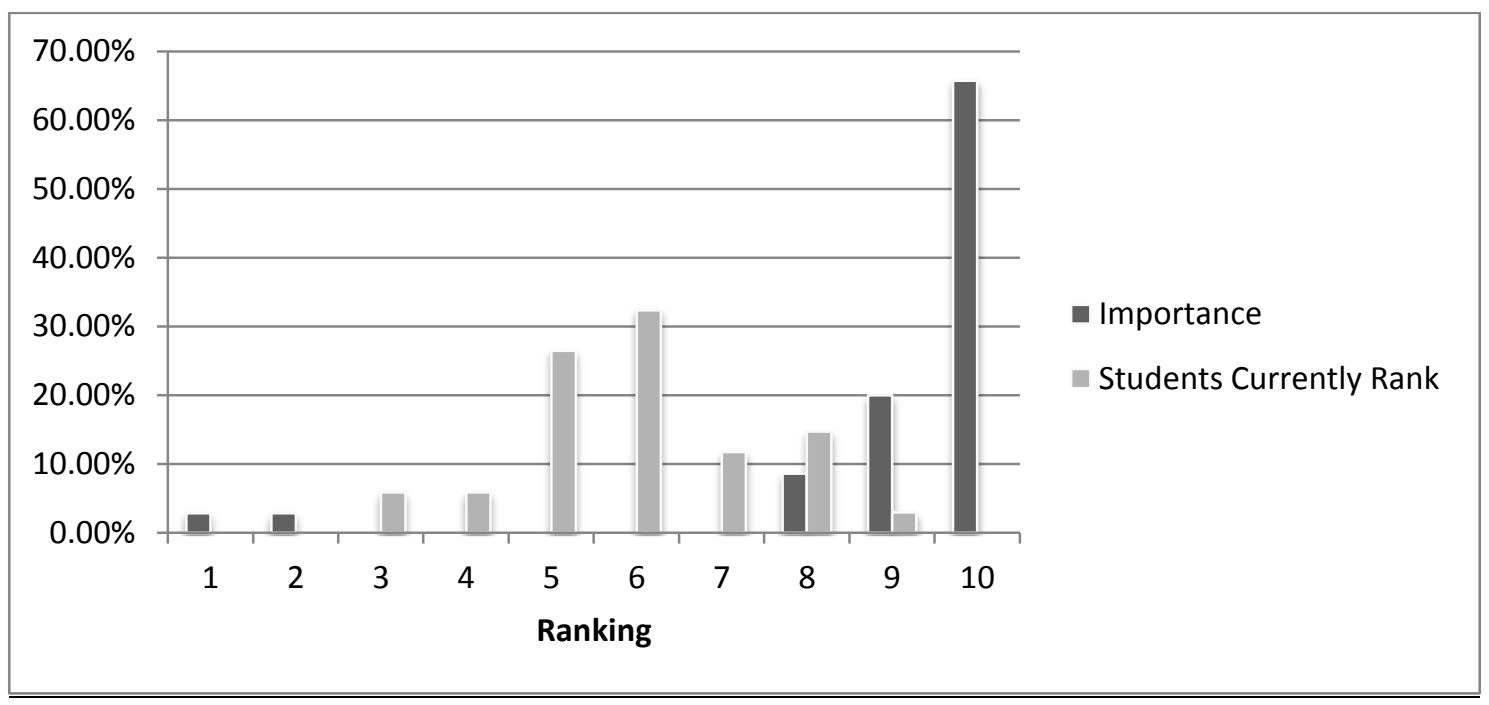

Figure 6: Critical Thinking

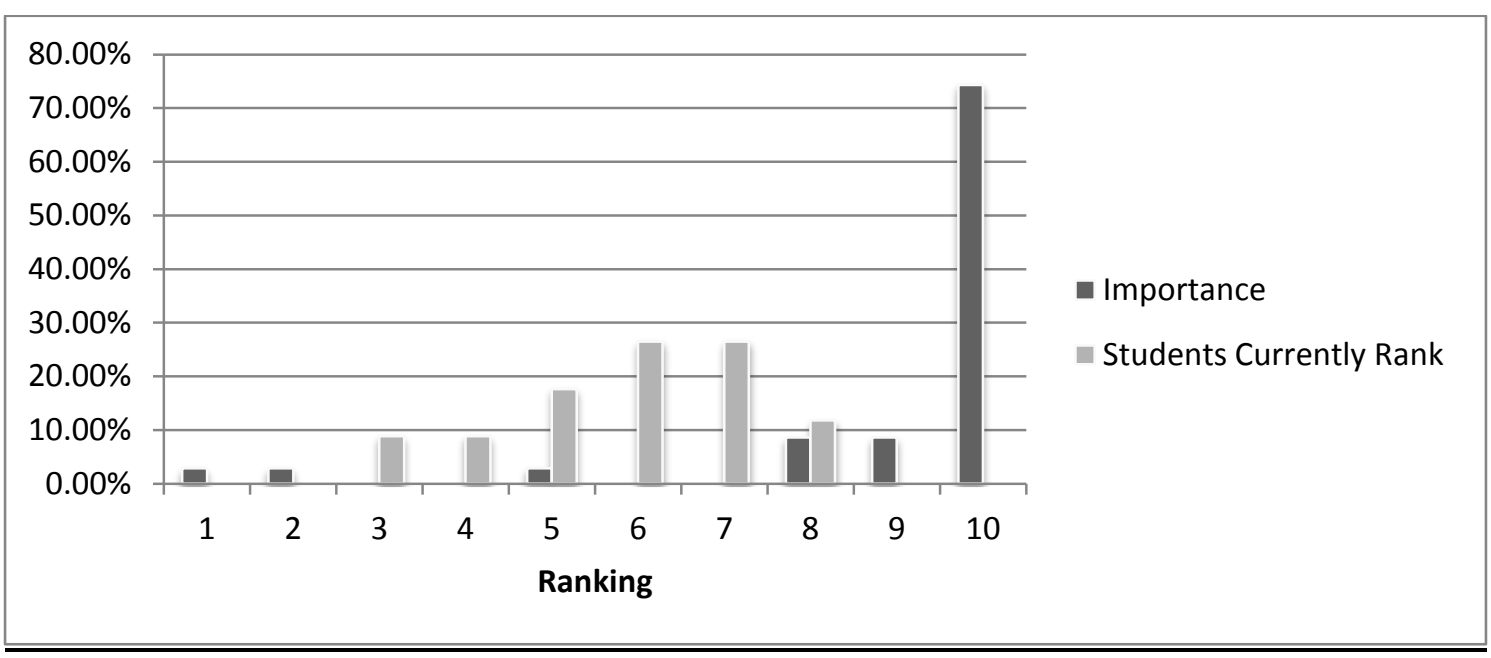

Figure 7: Reading Comprehension 


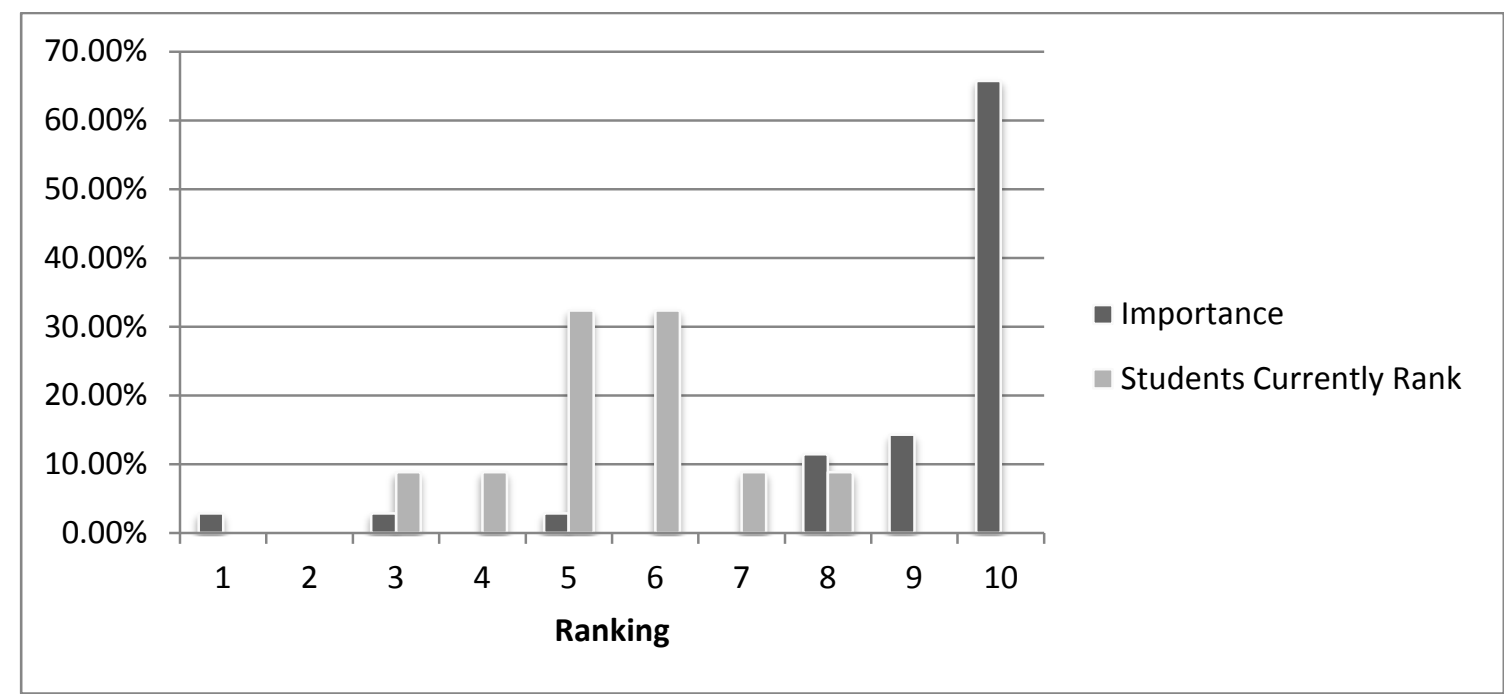

Figure 8: Effective Written Communication

\section{FUTURE RESEARCH}

Critical thinking, reading comprehension, and effective written communication are the top ranked critical skills. In addition, more needs to be done to ensure that students are acquiring these skills. Future research opportunities could include how to incorporate these three skills (and others) into the business curriculum and how one goes about assessing these skills.

In addition, it would be interesting to survey students and stakeholders such as employers on the skills that they view as most critical for business students to acquire. It would be curious to see if students and stakeholders would rank the skills differently than the faculty.

\section{CONCLUSIONS}

A critical skills survey and the survey results were presented. The purpose of the survey was to identify which critical skills business students need to have in order to be successful in their advanced coursework and careers. The survey was disseminated to faculty at various institutions. Faculty were asked to rank the importance of a particular skill and where their students currently rank in possessing this skill. Critical thinking, reading comprehension, and effective written communication are the highest ranked critical skills in terms of importance. Although these three skills are highly ranked, the survey results also indicate that there is still room for improvement in terms of making sure students are fully acquiring these skills. Finally, future research opportunities were discussed.

\section{AUTHOR INFORMATION}

Marsha Jance is an Assistant Professor of Business Administration at Indiana University East in Richmond, Indiana, USA. She received her Ph.D. in Management Science from Illinois Institute of Technology Stuart School of Business in Chicago. Jance has taught courses in statistics, spreadsheet and decision modeling, introduction to business, and first year seminar. Her primary research areas are in statistics and decision modeling. Jance can be reached at mjance@iue.edu (Corresponding author)

Anita Morgan is an Assistant Professor of Accounting at Indiana University East in Richmond, Indiana, USA. She received her DBA in Accounting from Nova Southeastern University and is a licensed CPA in the state of Indiana. She primarily teaches courses in accounting and has strong research interests in teaching with technology and assessment. Morgan can be reached at animorga@iue.edu 
NOTES 